\title{
Antibodies against citrullinated proteins in relation to periodontitis with or without rheumatoid arthritis: a cross-sectional study
}

\author{
Pit Hui Lew ${ }^{1}$, Mohammad Tariqur Rahman², Syarida Hasnur Safii ${ }^{1}$, Nor Adinar Baharuddin ${ }^{1}$, Peter Mark Bartold ${ }^{3}$,
} Sargunan Sockalingam ${ }^{4}$, Noor Lide Abu Kassim ${ }^{5}$ and Rathna Devi Vaithilingam ${ }^{1 *}$

\begin{abstract}
Background: Previous studies have reported conflicting findings between serum anti-citrullinated protein antibodies (ACPA) levels in rheumatoid arthritis (RA) participants with and without periodontitis (Pd). This study aimed to analyse possible correlations between serum ACPA levels and clinical parameters in Pd and RA participants.

Methods: Full mouth periodontal examination (probing pocket depth, clinical attachment levels, gingival bleeding index, visual plaque index) was conducted and serum samples obtained from 80 participants comprising RA, Pd, both RA and Pd (RAPd) and healthy individuals (HC). Erythrocyte sedimentation rates (ESR) and periodontal inflamed surface area (PISA) were obtained. Serum samples were analysed for ACPA quantification using enzyme-linked immunosorbent assay (ELISA).

Results: Median levels (IU/mL) of ACPA (interquartile range, IQR) in RAPd, RA, Pd and HC groups were 118.58(274.51), 102.02(252.89), 78.48(132.6) and 51.67(91.31) respectively. ACPA levels were significantly higher in RAPd and RA as compared to HC group $(p<0.05)$. However, ACPA levels of any of the groups were not correlated with any clinical periodontal and RA parameters within the respective groups.

Conclusions: At individual level, the amount of serum ACPA seem to have an increasing trend with the diseased condition in the order of RAPd $>$ RA $>$ Pd $>$ HC. However, lack of any significant correlation between the serum ACPA levels with the clinical Pd and RA parameters warrants further studies to investigate the causal link between RA and Pd for such a trend. Further studies involving more inflammatory biomarkers might be useful to establish the causal link between Pd in the development and progression of RA or vice versa.
\end{abstract}

Keywords: Anti-citrullinated protein antibodies (ACPA), Citrullination, Periodontitis, Rheumatoid arthritis

\section{Background}

Periodontitis (Pd) is a host-mediated chronic inflammatory disease associated with a dysbiotic dental biofilm and is characterised by both soft and hard tissue destruction around the teeth [1]. Current epidemiological evidence

\footnotetext{
*Correspondence: rathna@um.edu.my

${ }^{1}$ Department of Restorative Dentistry, Faculty of Dentistry, University

of Malaya, 50603 Kuala Lumpur, Malaysia

Full list of author information is available at the end of the article
}

suggests that Pd is moderately prevalent globally while its severe subtype displays a prevalence of $11.2 \%$ [2]. Rheumatoid arthritis (RA) is a chronic inflammatory autoimmune disease which is characterised by inflamed synovial tissues as well as destruction of cartilage and bone in the joints. It has a global prevalence of $1 \%$ and may lead to severe disabilities and early premature mortality as it progresses with age [3].

Numerous epidemiological and clinical studies have reported a significant association between Pd and RA 
whereby Pd is more common and severe in patients with established RA and vice versa $[4,5]$. Despite the differences in their initiating aetiological mechanisms, both chronic inflammatory conditions share a similar host mediated pathogenesis characterised by similar sets of pro-inflammatory cytokines, and risk factors (such as smoking, obesity and ageing), that justify a plausible link between them [6] which subsequently also impacts their oral health related quality of life $[7,8]$. However, the actual mechanisms through which RA and Pd are interrelated is still unclear.

Bright and colleagues [9] have proposed the dual hit hypothesis for pathogenesis of RA being driven by protein citrullination or carbamylation, or both, in inflamed periodontal tissues. Upon citrullination, a post translational modification of amino acid arginine to citrulline mediated by peptidyl arginine deiminase enzymes (PADs), citrullinated proteins evoke autoimmune response in a susceptible patient. As a result, pathogenic $\mathrm{T}$ and $\mathrm{B}$ cells are activated, leading to the formation of RA-specific anti-citrullinated protein antibodies (ACPA) [10]. Detection of these antibodies in the serum of participants with RA has been well documented [11, 12]. Interestingly, the presence of these same autoantibodies in the serum of participants with periodontitis has also been reported in several studies [13-15].

In view of the possible causal link between RA and Pd via citrullination, various studies have been carried out to assess and compare the ACPA levels in RA participants with and without Pd. In a case-control study conducted among a cohort of non-smoker RA participants, ACPA levels were reported to be significantly higher in RA participants with Pd than those without Pd, suggesting that Pd and high ACPA expression could serve as a potential environmental trigger in RA development [16]. However, two other studies conducted to investigate the levels of ACPA in RA participants with and without Pd did not find significantly higher levels of ACPA in RA-Pd participants as compared to RA non-Pd participants [17, 18]. As a result of these conflicting findings, this study was conducted to evaluate and compare the levels of serum ACPA in four groups of participants (RAPd, RA, Pd and $\mathrm{HC}$ groups) as well as to identify the possible association between RA and Pd by correlating the serum ACPA levels to both clinical RA and Pd parameters.

\section{Methods}

\section{Study design}

This was a cross-sectional comparative study conducted at Faculty of Dentistry, University of Malaya, Malaysia. Study was conducted in accordance with the Declaration of Helsinki. Ethics approval was obtained from the Medical Research Ethics Committee (MREC),
University Malaya Medical Centre (UMMC) [MRECID NO. 2017510-5227) and Medical Ethics Committee, University of Malaya's Faculty of Dentistry [DF-RD1707/0029(L)]. Participants were recruited between November 2017 and December 2018 from Primary Care Unit, Faculty of Dentistry, University of Malaya (Pd and HC groups) and Rheumatology Clinic, University Malaya Medical Centre (RA and RAPd groups).

\section{Sample size calculation}

Sample size calculation was performed based on the mean levels and standard deviations (SD) of serum ACPA in RA group $(86.0 \pm 73.0 \mathrm{U} / \mathrm{mL})$ and non-RA group $(7.5 \pm 7.4 \mathrm{U} / \mathrm{mL})$ reported by Karkucak [19]. The required number of samples stands at 20 for each group in order to provide $80 \%$ power at a significance level of $5 \%$.

\section{Participants recruitment}

A total of 80 participants (20 from each of four groups) who fulfilled the inclusion criteria were enrolled in this study (groups: RAPd group, RA group, Pd group, and $\mathrm{HC}$ group). The summary of the recruitment process and study design was demonstrated in flow chart (Fig. 1).

The primary inclusion criteria included: age $\geq 30$ years with at least eight teeth excluding third molars. All participants with RA met the 2010 RA Classification Criteria of the American College of Rheumatology/European League Against Rheumatism (ACR/EULAR) [20] with $>1$ year of diagnosis. In the Pd group, participants were diagnosed with moderate to severe chronic periodontitis [21] or Stage II to stage IV periodontitis [22]. In the RA and $\mathrm{HC}$ groups, participants were either periodontally healthy or had gingivitis with $\mathrm{PPD} \leq 3 \mathrm{~mm}$.

Exclusion criteria were pregnancy and lactation, concurrent systemic or debilitating medical conditions such as diabetes mellitus and other autoimmune diseases or malignancies, periodontal treatment within the past four months, and the use of antibiotics within the past four months. Written informed consent was obtained from each participant before the study.

\section{Standardisation of examiners}

Three trained and calibrated examiners including LPH (the first author of the manuscript) were involved in the patient examination and data collection. Kappa values of more than 0.75 was obtained by all three examiners for both intra-examiner and inter-examiner standardizations of PPD and CAL and thus were considered "reproducible" and "standardized". 


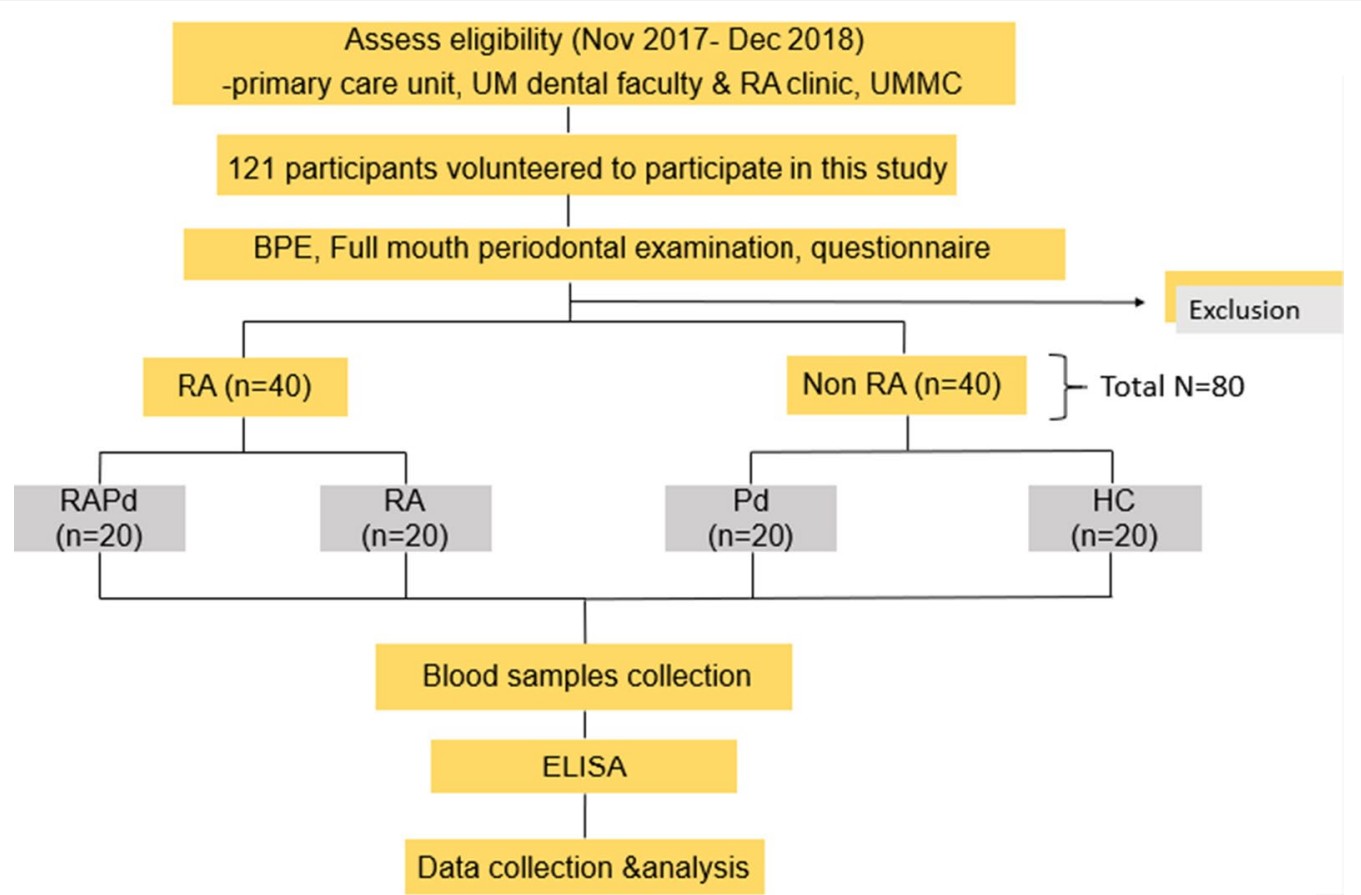

Fig. 1 Study flow chart showing the summary of the study design. RA, rheumatoid arthritis; Pd, periodontitis; RAPd group, subjects with RA and Pd; RA group, subjects with RA but without Pd; Pd group, subjects without RA but has Pd; HC group, subjects without both RA and Pd; UM, University of Malaya; UMMC, University of Malaya Medical Centre; BPE, basic periodontal examination; ELISA, enzyme link immunosorbent assay

\section{Clinical examination/measurements}

All participants were required to complete a questionnaire which consisted of socio-demographic information (age, gender, and ethnicity), medical and dental histories, including lifestyle practices or habits (smoking status and oral hygiene habits). Subsequently, all eligible participants were subjected to a full mouth periodontal examination on 6 sites (mesio-buccal, mid-buccal, disto-buccal, mesio-lingual/palatal, midlingual/palatal, disto-lingual/palatal) of each tooth. All teeth were examined except third molars.

Clinical periodontal parameters measured were Visible Plaque Index (VPI) [23], Gingival Bleeding Index (GBI) [23], Probing Pocket Depth (PPD) and Clinical Attachment Level (CAL). UNC 15 colour-coded periodontal probe (Hu-Friedy, Chicago, USA) was used in all the measurements. The amount of inflamed periodontal tissue was quantified as the periodontal inflamed surface area (PISA) whereby the surface area of bleeding pocket epithelium was calculated in square millimeters, illustrating the inflammatory burden posed by periodontitis [24, 25]. For RA participants, erythrocyte sedimentation rate (ESR), C-reactive protein (CRP), and disease duration of the disease were collected from their medical records.

\section{Enzyme Linked Immunosorbent Assay (ELISA)}

Peripheral blood $(10 \mathrm{~mL})$ was obtained from venous cubital fossa of each subject. After coagulation, the blood sample was centrifuged for $15 \mathrm{~min}$ at $1000 \times \mathrm{g}$. The serum was aliquoted into labelled microcentrifuge tubes (1.5 $\mu \mathrm{L})$ and stored at $-80{ }^{\circ} \mathrm{C}$ until analysis. Commercially available ELISA kits (Human CCP-Ab ELISA Kits; Elabscience, Wuhan, China) were used to analyse serum samples for the presence and quantification of ACPA. ELISA was performed following the manufacturer's instructions. Briefly, the diluted samples were incubated in the precoated ELISA plates. Standards or samples were added to the appropriate ELISA plate wells and combined with the specific antigen. Then, a biotinylated detection antigen specific for ACPA and Avidin-Horseradish Peroxidase (HRP) conjugate were added to each microplate well successively and incubated. After incubation, free components were washed away. Then, the substrate solution was added to each well. The enzyme-substrate reaction is terminated by adding a stop solution. All standards and serum samples were assayed in triplicates. The absorbance was recorded using a microplate reader at $450 \mathrm{~nm}$ wavelength. Standard curve was generated using standard optical density (OD). The OD value is proportional to the concentration of ACPA. The concentration of ACPA 
in serum samples was determined by comparing the OD of the samples to the standard curve. The cut off value for ACPA positivity was $68.73 \pm 52.49 \mathrm{IU} / \mathrm{mL}$.

\section{Statistical analyses}

Statistical analysis was performed using SPSS 25.0 statistical software (IBM, Chicago, IL, USA). All the metric demographic and clinical data were checked for normal distribution using the Kolmogorov-Smirnov test. Oneway ANOVA was used to compare VPI, GBI, PPD and CAL between the four groups while Kruskal-Wallis test was used for PISA comparison between groups. Since the ESR was normally distributed, independent sample $T$ test was used to compare the mean ESR between RAPD and RA groups.

ACPA levels for all participants were plotted as median and interquartile range (IQR) as all metric values were not normally distributed. For statistical evaluation of the pairwise difference, the Pairwise Mann-Whitney $U$ test was used to compare the medians of ACPA levels between groups for all possible pairs. The differences in the distributions of categorical outcomes were analysed using the Pearson chi-square test while differences in continuous outcomes between the four groups were determined by using one-way ANOVA test. The correlation between the serum level of ACPA and clinical periodontal and RA parameters were evaluated using Spearman rho correlation test. All tests were two-sided, and results with $p<0.05$ were considered statistically significant at $95 \%$ confidence interval (CI).

\section{Results}

\section{Characteristics of participants}

Participants from the Pd and $\mathrm{HC}$ groups were generally younger than RA group. Most participants in all four groups were females while those in the RAPd and Pd groups were diagnosed with localised moderate to severe $\mathrm{Pd}$. Although the minimum number of teeth required in our study was 8 teeth, all the participants involved in this study had at least 13 teeth.

There were statistically significant differences in age and gender between the four groups $(p<0.05)$, however, no statistically significant differences were observed for education level, ethnicity, smoking status, mean ESR, duration of RA and types of RA medication used (Table 1).

\section{Clinical periodontal parameters}

The mean $( \pm \mathrm{SD})$ PISA was found to be the highest in the Pd group $\left(1148.53 \pm 782.47 \mathrm{~mm}^{2}\right)$ followed by RAPd group and $\mathrm{HC}$ group. The RA group was found to have the lowest mean PISA score among the four groups with the mean values of $102.09 \pm 96.56 \mathrm{~mm}^{2}$. Pd group was found to have the highest mean PPD and CAL followed by RAPd group. On the other hand, both the RA and HC groups were found to have similar mean values of PPD and CAL, which were much lower than the periodontitis group as expected. Statistically significant differences $(p<0.05)$ were observed for all the clinical periodontal parameters measured (VPI, GBI, PPD, CAL and PISA) between the four groups of participants (Table 2).

\section{Serum ACPA levels}

The serum ACPA levels for all four groups are shown in a boxplot (Fig. 2). Median (IQR) for RAPd group was 118.58(274.51) IU/mL, RA group was 102.02(252.89) IU/ $\mathrm{mL}$, Pd group was $78.48(132.6) \mathrm{IU} / \mathrm{mL}$, and $\mathrm{HC}$ group was 51.67(91.31) IU/mL. Serum ACPA level was significantly higher in RAPd, and RA group compared to that of $\mathrm{HC}$. There is an increase in ACPA levels from HC group, Pd group, RA group to RAPd group. At individual level, the amount of serum ACPA seem to have an increasing trend with the diseased condition in the order of $\mathrm{RAPd}>\mathrm{RA}>\mathrm{Pd}>\mathrm{HC}$ (Fig. 3).

\section{Correlation analysis between ACPA and clinical disease parameters}

Bivariate correlation analyses were performed to assess the relationship between serum ACPA levels and recorded clinical parameters of RA (Table 3) and Pd (Table 4). In both RAPd and RA groups, there were no correlations between the serum ACPA levels with ESR and RA disease duration $(\mathrm{r}<0.30 ; p>0.05)$. Similarly, this present study also demonstrated no significant correlations between serum levels of ACPA with all the clinical periodontal parameters (VPI, GBI, PPD, CAL and PISA) in all the four groups of participants $(\mathrm{r}<0.30 ; p>0.05)$. Multiple regression analyses were further performed to assess these correlations after adjusting for confounding factors (age, gender, ethnicity, and smoking status) (Additional file 1: Tables S1 and S2). However, these confounding factors did not contribute significantly to the model and were not potential predictors for the variability in serum ACPA, RA parameters and Pd clinical parameters.

\section{Discussion}

In this cross-sectional comparative study, serum ACPA levels were compared between patients who were diagnosed with Pd, RA, and RAPd. The levels of serum ACPA, from higher to lower, were recorded as follows: $\mathrm{RAPd}>\mathrm{RA}>\mathrm{Pd}>\mathrm{HC}$ group. The levels of serum ACPA were found to be statistically significantly higher in the RA cohorts (both RAPd and RA groups) as compared to the HC group. Importantly, high serum ACPA levels in those diagnosed with RA have been demonstrated in other studies [19, 26], It is an established fact that ACPA 
Table 1 Sample characteristics of study population

\begin{tabular}{|c|c|c|c|c|c|}
\hline Group/Characteristics & $\begin{array}{l}\text { RAPd } \\
(n=20)\end{array}$ & $\begin{array}{l}\text { RA } \\
(n=20)\end{array}$ & $\begin{array}{l}P d \\
(n=20)\end{array}$ & $\begin{array}{l}\mathrm{HC} \\
(\mathrm{n}=20)\end{array}$ & $p$-value \\
\hline Mean age (years) & $54.3 \pm 7.5$ & $52.7 \pm 9.5$ & $44.0 \pm 11.6$ & $39.6 \pm 11.5$ & $* *<0.00^{a}$ \\
\hline \multirow[t]{2}{*}{ Mean ESR (mm/hr) } & $32.8 \pm 21.4$ & $27.9 \pm 11.6$ & N/A & N/A & $0.379^{b}$ \\
\hline & n (\%) & n (\%) & $\mathrm{n}(\%)$ & $\mathrm{n}(\%)$ & \\
\hline \multicolumn{6}{|l|}{ Gender } \\
\hline Female & $14(70)$ & $19(95)$ & $11(55)$ & $16(80)$ & ${ }^{* *} 0.028^{c}$ \\
\hline Male & $6(30)$ & $1(5)$ & $9(45)$ & $4(20)$ & \\
\hline \multicolumn{6}{|l|}{ Ethnicity } \\
\hline Malay & $4(20)$ & $7(35)$ & $9(45)$ & $13(65)$ & $0.086^{c}$ \\
\hline Chinese & $11(55)$ & $7(35)$ & $9(45)$ & $5(25)$ & \\
\hline Indian & $5(25)$ & $6(30)$ & $2(10)$ & $2(10)$ & \\
\hline \multicolumn{6}{|l|}{ Educational level } \\
\hline Tertiary & $6(30)$ & $13(65)$ & $13(65)$ & $18(90)$ & $0.050^{c}$ \\
\hline Secondary & $14(70)$ & $6(30)$ & $7(35)$ & $2(10)$ & \\
\hline Primary & $0(0)$ & $1(5)$ & $0(0)$ & $0(0)$ & \\
\hline \multicolumn{6}{|l|}{ Smoking status } \\
\hline Smoker & $2(10)$ & $0(0)$ & $3(15)$ & $3(15)$ & $0.457^{c}$ \\
\hline Former smoker & $2(10)$ & $0(0)$ & $1(5)$ & $1(5)$ & \\
\hline Non-smoker & $16(80)$ & $20(100)$ & $16(80)$ & $16(80)$ & \\
\hline \multicolumn{6}{|l|}{ RA disease duration } \\
\hline$<5$ & $8(40)$ & $7(35)$ & $\mathrm{N} / \mathrm{A}$ & $\mathrm{N} / \mathrm{A}$ & $0.587^{c}$ \\
\hline $5-10$ & $6(30)$ & $9(45)$ & $\mathrm{N} / \mathrm{A}$ & N/A & \\
\hline$>10$ years & $6(30)$ & $4(20)$ & N/A & $\mathrm{N} / \mathrm{A}$ & \\
\hline $\begin{array}{l}\text { RA medication } \\
\text { Corticosteroid } \\
\text { NSAIDs } \\
\text { Conventional DMARDs } \\
\text { Biologic DMARDs } \\
\text { Combination }\end{array}$ & $\begin{array}{l}1(5) \\
3(15) \\
7(35) \\
0(0) \\
6(30)\end{array}$ & $\begin{array}{l}0(0) \\
2(10) \\
9(40) \\
1(5) \\
5(25)\end{array}$ & $\begin{array}{l}\text { N/A } \\
\text { N/A } \\
\text { N/A } \\
\text { N/A } \\
\text { N.A }\end{array}$ & $\begin{array}{l}\text { N/A } \\
\text { N/A } \\
\text { N/A } \\
\text { N/A } \\
\text { N/A }\end{array}$ & $0.632^{c}$ \\
\hline \multicolumn{6}{|l|}{ PD status } \\
\hline Localised Pd & $17(85)$ & N/A & $14(70)$ & $\mathrm{N} / \mathrm{A}$ & $0.110^{c}$ \\
\hline Generalised Pd & $3(15)$ & $\mathrm{N} / \mathrm{A}$ & $6(30)$ & $\mathrm{N} / \mathrm{A}$ & \\
\hline
\end{tabular}

RA, Rheumatoid arthritis; Pd, Periodontitis; RAPd group, Subjects with RA and Pd; RA group, Subjects with RA but without Pd; Pd group, Subjects without RA but has $\mathrm{Pd}$; HC group, Subjects without both RA and Pd; ESR, Erythrocyte sedimentation rate; NSAIDs, Non-steroidal anti-inflammatory drugs; DMARDs, Disease modifying antirheumatic drugs

a One-way ANOVA

${ }^{\mathrm{b}}$ Independent sample $T$-test

c Pearson Chi-square test

**Statistically significant at $p<0.05$

are present in early RA disease and are highly specific for RA [27]. Biologically, ACPA have been shown to be involved in the inflammatory processes that occur in RA $[28,29]$. This finding also reaffirms ACPA as a specific serological marker in RA pathogenesis [12]. Furthermore, earlier it was reported that ACPA may be detectable at low levels in about $1-3 \%$ of healthy individuals without any joint symptoms [30, 31].

It has been proposed that periodontal pathogenesis contributes to systemic inflammation by generating citrullinated proteins in inflamed periodontal tissues, subsequently leading to the formation of ACPA [6, 32]. Over the years, researchers have attempted to find possible associations between $\mathrm{RA}$ and $\mathrm{Pd}$ in relation to ACPA (a common serological marker for RA) and clinical parameters of periodontitis. However, the current study did not show any statistically significant correlations between serum ACPA levels and common clinical Pd parameters namely, VPI, GBI, PPD, CAL and PISA. Similar findings were also reported in earlier studies [33, 
Table 2 Comparison of the clinical periodontal parameters between groups

\begin{tabular}{|c|c|c|c|c|c|}
\hline \multirow[t]{2}{*}{$\begin{array}{l}\text { Periodontal } \\
\text { parameters }\end{array}$} & $\begin{array}{l}\text { RAPd } \\
(n=20)\end{array}$ & \multirow{2}{*}{$\begin{array}{l}\text { RA } \\
(n=20) \\
\text { Means } \pm S D\end{array}$} & \multirow{2}{*}{$\begin{array}{l}P d \\
(n=20) \\
\text { Means } \pm \text { SD }\end{array}$} & \multirow{2}{*}{$\begin{array}{l}\mathrm{HC} \\
(\mathrm{n}=20) \\
\text { Means } \pm S D\end{array}$} & \multirow[t]{2}{*}{$p$-value } \\
\hline & Means \pm SD & & & & \\
\hline VPI (\%) & $55.24 \pm 25.13$ & $36.04 \pm 23.17$ & $55.18 \pm 26.94$ & $28.47 \pm 20.78$ & ${ }^{* *} 0.001^{\mathrm{a}}$ \\
\hline GBI (\%) & $33.52 \pm 23.41$ & $7.29 \pm 6.54$ & $40.02 \pm 24.45$ & $12.92 \pm 15.39$ & $*^{* *}<0.001^{\mathrm{a}}$ \\
\hline PPD (mm) & $3.07 \pm 0.72$ & $1.92 \pm 0.28$ & $3.62 \pm 0.92$ & $1.95 \pm 0.32$ & ${ }^{* *}<0.001^{\mathrm{a}}$ \\
\hline $\mathrm{CAL}(\mathrm{mm})$ & $3.77 \pm 1.12$ & $0.61 \pm 0.10$ & $4.33 \pm 1.78$ & $0.63 \pm 0.19$ & ${ }^{* *}<0.001^{\mathrm{a}}$ \\
\hline PISA $\left(\mathrm{mm}^{2}\right)$ & $772.83 \pm 619.45$ & $102.09 \pm 96.56$ & $1148.53 \pm 782.47$ & $202.80 \pm 137.76$ & $*^{* *}<0.001^{b}$ \\
\hline
\end{tabular}

RA, Rheumatoid arthritis; Pd, Periodontitis; RAPd group, Subjects with RA and Pd; RA group, Subjects with RA but without Pd; PD group, Subjects without RA but has Pd; HC group, Subjects without both RA and Pd; VPI, Visible plaque index; GBI, Gingival bleeding index; PPD, Probing pocket depth; CAL, Clinical attachment level; PISA, Periodontal inflamed surface area

a One-way ANOVA

${ }^{\mathrm{b}}$ Kruskal- Wallis Test

**Statistically significant at $p<0.05$

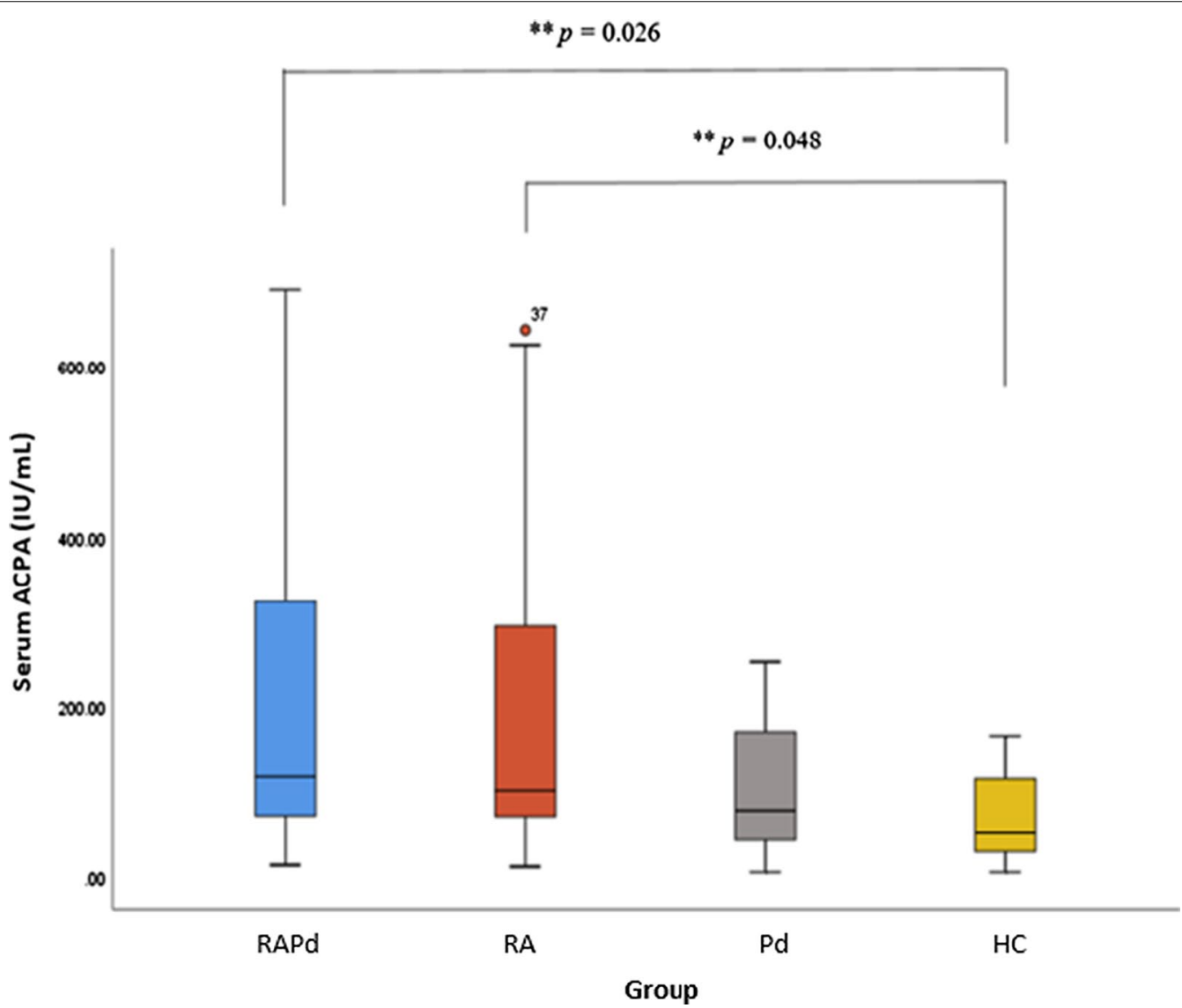

Fig. 2 Boxplots of the serum anti-citrullinated protein antibody (ACPA) levels in four groups of subjects. The medians of ACPA levels between the groups were compared with Kruskal-Wallis test (between group, $p=0.005$ ), which indicates significant difference between groups at $p<0.05$. Pairwise Mann-Whitney U-test ** ${ }^{*}$ statistically significant difference inter-group at $p<0.05$

34]. It is to be noted that serum ACPA levels of Pd and HC groups are not significantly different. Hence, it is not unlikely that serum ACPA level does not correlate with periodontal clinical parameters. This is contrary to the other studies where a statistically significant correlation between serum ACPA and Pd parameters [16, 30] were shown. 


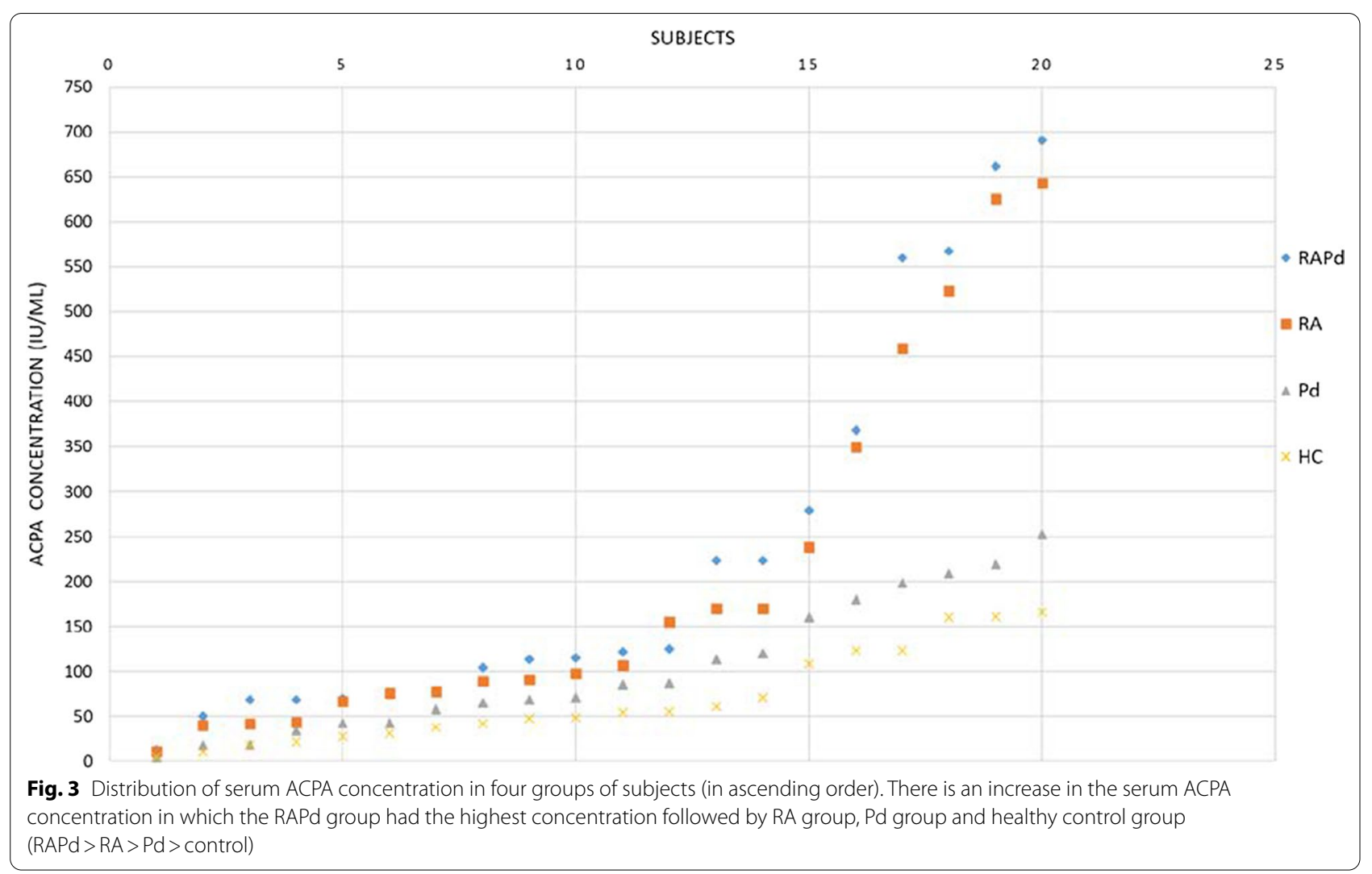

Taken together, it can be concluded that serum ACPA levels are more influenced by RA pathogenesis than that of Pd. Notably, generation of ACPA in RA and Pd is expected to be different. This is based on the notion that, ACPA is the product of host mediated citrullination in RA, while the same has been suggested to be a product of citrullination mediated by the periodontal pathogens in periodontitis.

In view of the plausibility of $\mathrm{Pd}$ as a risk factor that causes systemic inflammatory responses and cross reactivity in RA [35, 36], PISA was calculated to quantify the amount of inflamed periodontal tissue and as such, quantifies the systemic inflammatory burden. Following this biological model, the larger the amount of inflamed periodontal tissue there is, the higher the chances of Pd eliciting systemic inflammatory responses and autoimmune responses [37] that may contribute to the increased ACPA levels. Once again, the current study did not find any statistically significant correlations between serum levels of ACPA with PISA in all four groups. This could be due to the recruitment of gingivitis cases in our healthy control group which has contributed to a higher PISA score in HC group than the RA group. Furthermore, PISA might not be the sole determinant in predicting the plausibility of Pd as a risk factor for systemic disease even though it can measure the amount of inflamed periodontal tissues. For instance, the type of inflammation might be more crucial than the amount of inflammation as PISA does not consider the types of microflora, cells, proteins and inflammatory mediators that might play a key role in causing inflammation [24, 38]. Our study groups of Pd and RA were also heterogenous as they come from different ethnic groups.

Like earlier reports, the current study demonstrated that serum ACPA and ESR (a common clinical parameter for RA) of RAPd and RA groups are not corelated $[39,40]$. This finding reaffirms the notion that the quality of the ACPA response defined by molecular characteristics or functional features of ACPA expressing autoreactive B cells are much more important and relevant than its quantity (serum level of ACPA) in determining the outcome of established RA. It has been shown that the fluctuations in serum ACPA levels do not reflect RA disease activity and are not clinically useful in predicting the progression and flare-up of the disease [41]. Therefore, measurements of serum ACPA may not be useful in monitoring RA disease activity. This warrants more research to develop more inflammatory markers for RA. 


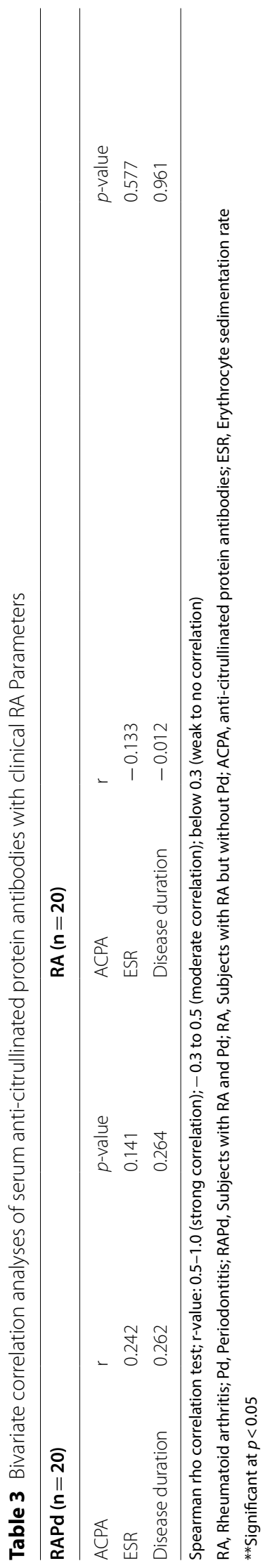


Table 4 Bivariate correlation analyses of serum anti-citrullinated protein antibodies with clinical periodontal parameters

\begin{tabular}{|c|c|c|c|c|c|c|c|c|}
\hline \multirow[b]{2}{*}{ ACPA } & \multicolumn{2}{|c|}{$\operatorname{RAPd}(n=20)$} & \multicolumn{2}{|c|}{$\mathrm{RA}(\mathrm{n}=20)$} & \multicolumn{2}{|c|}{$\operatorname{Pd}(n=20)$} & \multicolumn{2}{|c|}{$H C(n=20)$} \\
\hline & $r$ & $p$-value & $r$ & $p$-value & $r$ & $p$-value & $r$ & $p$-value \\
\hline VPI & 0.228 & 0.334 & 0.254 & 0.28 & 0.119 & 0.618 & 0.085 & 0.723 \\
\hline $\mathrm{GBI}$ & 0.052 & 0.828 & -0.030 & 0.90 & 0.045 & 0.850 & -0.058 & 0.808 \\
\hline PPD & -0.03 & 0.899 & -0.057 & 0.811 & 0.051 & 0.830 & -0.182 & 0.441 \\
\hline $\begin{array}{l}\text { CAL } \\
\text { PISA }\end{array}$ & $\begin{array}{l}0.099 \\
0.211\end{array}$ & $\begin{array}{l}0.678 \\
0.373\end{array}$ & $\begin{array}{l}0.275 \\
0.137\end{array}$ & $\begin{array}{l}0.240 \\
0.565\end{array}$ & $\begin{array}{l}0.107 \\
-0.032\end{array}$ & $\begin{array}{l}0.654 \\
0.895\end{array}$ & $\begin{array}{l}-0.201 \\
-0.093\end{array}$ & $\begin{array}{l}0.196 \\
0.698\end{array}$ \\
\hline
\end{tabular}

Spearman rho correlation test; r-value: $0.5-1.0$ (strong correlation); - 0.3 to 0.5 (moderate correlation); below 0.3 (weak to no correlation)

RA, Rheumatoid arthritis; Pd, Periodontitis; RAPd, Subjects with RA and Pd; RA, Subjects with RA but without Pd; Pd, Subjects without RA but has Pd; HC, Subjects without both RA and Pd; ACPA, anti-citrullinated protein antibodies; VPI, visible plaque index; GBI, gingival bleeding index; PPD, probing pocket depth; CAL, clinical attachment level

**Significant at $p<0.05$

Given the sample number and contradictory observations with the existing literature, it might not be prudent to extrapolate the current observation at a population level. While the current study warrants further investigation with larger samples to resolve whether the contradiction is solely due to the limited sample size. Future study that using a larger sample size from multiple centres may provide better validation of the findings. Moreover, inclusion of additional data on the inflammatory markers such as DAS-28 and CRP could have been more useful to analyse the severity of RA pathogenesis. Although ESR is a good inflammatory marker that can reflect RA disease activity over the preceding weeks, it could be affected by other confounding factors such as age, gender, fibrinogen levels and rheumatoid factor (RF) [42]. Lastly, none of the case definitions/classifications that are being used currently suffice to define the degree of inflamed periodontal tissue and hence may not be able to quantify the inflammatory burden posed by periodontitis. Thus, it is proposed that PISA can be used in conjunction with the case definition/classification when Pd is investigated as a potential risk factor for RA or any other systemic diseases.

\section{Conclusion}

Lack of correlation between ACPA with the clinical parameters of Pd suggests that citrullination of proteins during Pd pathogenesis might not be sufficient to make a mechanistic or causal link between RA and Pd. Further studies using more sensitive biomarkers that are common in both clinical conditions are needed to establish the role of Pd in the development and progression of RA.

\section{Abbreviations}

ACPA: Anti-citrullinated protein antibodies; ACR/EULAR: American College of Rheumatology/European League Against Rheumatism; BOP: Bleeding on probing; CAL: Clinical attachment loss; Cl: Confidence interval; CRP: C-reactive protein; DAS: Disease activity score; DMARDs: Disease modifying antirheumatic drugs; ELISA: Enzyme-linked immunosorbent assay; ESR: Erythrocyte sedimentation rate; GBI: Gingival Bleeding Index; HC: Subjects without RA and Pd/healthy individuals; IQR: Interquartile range; MREC: Medical Research Ethics Committee; NSAIDs: Non-steroidal anti-inflammatory drugs; OD: Optical density; PADs: Peptidyl arginine deiminase enzymes; Pd: Periodontitis; PISA: Periodontal inflamed surface area; PPD: Probing pocket depth; RA: Rheumatoid arthritis; RAPd: Participants with RA and Pd; RF: Rheumatoid factor; SD: Standard deviation; SPSS: Statistical Package of Social Sciences; UMMC: University of Malaya Medical Centre; VPI: Visible Plaque Index.

\section{Supplementary Information}

The online version contains supplementary material available at https://doi. org/10.1186/s12903-021-01712-y.

Additional file 1: Table S1. Multiple linear regression analysis models for ACPA, ESR and disease duration controlling for age, gender, ethnicity, and smoking status in the RAPd and RA groups. These confounding factors did not contribute significantly to the model. RAPd: Subjects with RA and Pd; RA: Subjects with RA but without Pd; ACPA: anticitrullinated protein antibodies; ESR: Erythrocyte sedimentation rate; Multiple linear regression analysis, ${ }^{* *}$ significant at $p<0.05 ; \mathrm{B}=$ Unstandardised regression coefficients; $\beta=$ Standardised regression coefficients; $\mathrm{Cl}=$ Confidence interval. Table S2. Multiple regression analysis models for periodontal parameters controlling for age, gender, ethnicity, and smoking status in all groups (RAPd, RA, Pd and HC). All these confounding factors did not contribute significantly to the model and were not potential predictors for the variability in clinical periodontal parameters. RAPd: Subjects with RA and Pd; RA: Subjects with RA but without Pd; Pd: Subjects without RA but has Pd; HC: Subjects without both RA and Pd; VPI: visible plaque index; GBI: gingival bleeding index; PPD: probing pocket depth; CAL: clinical attachment level; PISA: Periodontal inflamed surface area; Multiple linear regression analysis, ${ }^{* *}$ significant at $p<0.05 ; \mathrm{B}=$ Unstandardised regression coefficients; $\beta=$ Standardised regression coefficients; $\mathrm{Cl}=$ Confidence interval.

\section{Acknowledgements}

Not applicable 


\section{Authors' contributions}

$\mathrm{LPH}$ was responsible for researching the topic background, data collection, analysis and writing the manuscript. RDV, MTR, NAB, SS and PMB conceived and designed the study, revised, and made worthy corrections of the manuscript. MTR, RDV, SHS assisted in the laboratory procedures and data collection process. NLAK assisted in the data collection and analysis process. All authors read and approved the final manuscript.

\section{Funding}

This research was funded by Fundamental Research Grant Scheme (FP0172017A) and Frontier Research Grant University of Malaya (FG040-17AFR).

\section{Availability of data and materials}

The datasets generated during and analyzed during the current study are not publicly available due to containing information that could compromise the privacy of research participants but are available from the corresponding author on reasonable request.

\section{Declarations}

\section{Ethics approval and consent to participate}

The study was designed according to the "Declaration of Helsinki". Ethical approval was obtained from the Medical Research Ethics Committee (MREC), University of Malaya Medical Centre (UMMC) [MRECID NO. 2017510-5227) and Medical Ethics Committee, University of Malaya's Faculty of Dentistry [DF-RD1707/0029(L)]. Written informed consent was obtained from each participant before the study.

\section{Consent for publication}

Not applicable.

\section{Competing interests}

All authors have no competing interest to declare.

\section{Author details}

${ }^{1}$ Department of Restorative Dentistry, Faculty of Dentistry, University of Malaya, 50603 Kuala Lumpur, Malaysia. ${ }^{2}$ Dean's Office, Faculty of Dentistry, University of Malaya, 50603 Kuala Lumpur, Malaysia. ${ }^{3}$ Department of Dentistry, University of Adelaide, Adelaide, Australia. ${ }^{4}$ Department of Rheumatology, Faculty of Medicine, University of Malaya, 50603 Kuala Lumpur, Malaysia. ${ }^{5}$ Kulliyyah of Education, International Islamic University Malaysia, 53100 Kuala Lumpur, Malaysia.

Received: 21 February 2021 Accepted: 7 July 2021

Published online: 20 July 2021

\section{References}

1. Bartold PM, Van Dyke TE. Periodontitis: a host-mediated disruption of microbial homeostasis. Unlearning learned concepts. Periodontol 2000. 2013; 62(1):203-17.

2. Kassebaum NJ, Bernabe E, Dahiya M, Bhandari B, Murray CJ, Marcenes W. Global burden of severe periodontitis in 1990-2010: a systematic review and meta-regression. J Dent Res. 2014;93(11):1045-53.

3. Scott DL, Wolfe F, Huizinga TW. Rheumatoid arthritis. Lancet (London). 2010;376(9746):1094-108

4. Detert J, Pischon N, Burmester GR, Buttgereit F. The association between rheumatoid arthritis and periodontal disease. Arthritis Res Ther. 2010;12:218.

5. Pischon N, Pischon T, Kroger J, Gulmez E, Kleber BM, Bernimoulin JP, et al. Association among rheumatoid arthritis, oral hygiene, and periodontitis. J Periodontol. 2008;79(6):979-86.

6. Lee YH, Lew PH, Cheah CW, Rahman MT, Baharuddin NA, Vaithilingam RD Potential mechanisms linking periodontitis to rheumatoid arthritis. J Int Acad Periodontol. 2019;21(3):99-110.

7. Han PSH, Saub R, Baharuddin NA, Sockalingam S, Bartold PM, Vaithilingam RD. Impact of periodontitis on quality of life among subjects with rheumatoid arthritis: a cross sectional study. BMC Oral Health. 2020;20:332.
8. Abdullah NS, Radzali NFM, Saub R, Vaithilingam RD. Oral health related quality of life and periodontal status of a selected Malaysian adult population: a pilot study. Ann Dent UM. 2013;2:16-23.

9. Bright R, Proudman SM, Rosenstein ED, Bartold PM. Is there a link between carbamylation and citrullination in periodontal disease and rheumatoid arthritis? Med Hypotheses. 2015;84(6):570-6.

10. Schellekens $G A$, de Jong $B A$, van den Hoogen $F H$, van de Putte $L B$, van Venrooij WJ. Citrulline is an essential constituent of antigenic determinants recognized by rheumatoid arthritis-specific autoantibodies. J Clin Invest. 1998;101(1):273-81.

11. Nishimura K, Sugiyama D, Kogata Y, Tsuji G, Nakazawa T, Kawano S, et al. Meta-analysis: diagnostic accuracy of anti-cyclic citrullinated peptide antibody and rheumatoid factor for rheumatoid arthritis. Ann Intern Med. 2007;146(11):797-808.

12. Mangat $P$, Wegner $N$, Venables PJ, Potempa J. Bacterial and human peptidylarginine deiminases: targets for inhibiting the autoimmune response in rheumatoid arthritis? Arthritis Res Ther. 2010;12:209.

13. Lappin DF, Apatzidou D, Quirke AM, Oliver-Bell J, Butcher JP, Kinane DF, et al. Influence of periodontal disease, Porphyromonas gingivalis and cigarette smoking on systemic anti-citrullinated peptide antibody titres. J Clin Periodontol. 2013;40(10):907-15.

14. Hendler A, Mulli TK, Hughes FJ, Perrett D, Bombardieri M, Houri-Haddad $Y$, et al. Involvement of autoimmunity in the pathogenesis of aggressive periodontitis. J Dent Res. 2010;89(12):1389-94.

15. Havemose-Poulsen A, Westergaard J, Stoltze K, Skjodt H, DanneskioldSamsoe B, Locht H, et al. Periodontal and hematological characteristics associated with aggressive periodontitis, juvenile idiopathic arthritis, and rheumatoid arthritis. J Periodontol. 2006;77(2):280-8.

16. Potikuri D, Dannana KC, Kanchinadam S, Agrawal S, Kancharla A, Rajasekhar $\mathrm{L}$, et al. Periodontal disease is significantly higher in nonsmoking treatment-naive rheumatoid arthritis patients: results from a case-control study. Ann Rheum Dis. 2012;71(9):1541-4.

17. Dissick A, Redman RS, Jones M, Rangan BV, Reimold A, Griffiths GR, et al. Association of periodontitis with rheumatoid arthritis: a pilot study. J Periodontol. 2010;81(2):223-30.

18. Laugisch O, Wong A, Sroka A, Kantyka T, Koziel J, Neuhaus K, et al. Citrullination in the periodontium-a possible link between periodontitis and rheumatoid arthritis. Clin Oral Investig. 2016;20(4):675-83.

19. Karkucak M. Serum levels of anti-citrullinated protein antibody (ACPA) and TWEAK in patients with rheumatoid arthritis: association with disease activity and treatment modalities. Turk J Rheuma. 2011;26(3):204-9.

20. Aletaha D, Neogi T, Silman AJ, Funovits J, Felson DT, Bingham CO, et al. 2010 Rheumatoid arthritis classification criteria: an American College of Rheumatology/European League Against Rheumatism collaborative initiative. Ann Rheum Dis. 2010;69(9):1580-8.

21. Armitage GC. Development of a classification system for periodontal diseases and conditions. Ann Periodontol. 1999;4(1):1-6.

22. Caton JG, Armitage G, Berglundh T, Chapple ILC, Jepsen S, Kornman $\mathrm{KS}$, et al. A new classification scheme for periodontal and peri-implant diseases and conditions - Introduction and key changes from the 1999 classification. J Clin Periodontol. 2018;45(S20):S1-8.

23. Ainamo J, Bay I. Problems and proposals for recording gingivitis and plaque. Int Dent J. 1975;25(4):229-35.

24. Nesse W, Abbas F, van der Ploeg I, Spijkervet FK, Dijkstra PU, Vissink A. Periodontal inflamed surface area: quantifying inflammatory burden. J Clin Periodontol. 2008;35(8):668-73.

25. Hujoel PP, White BA, Garcia RI, Listgarten MA. The dentogingival epithelial surface area revisited. J Periodont Res. 2001;36(1):48-55.

26. Zendman AJ, van Venrooij WJ, Pruijn GJ. Use and significance of anti-CCP autoantibodies in rheumatoid arthritis. Rheumatology. 2006;45(1):20-5.

27. Firestein GS, McInnes IB. Immunopathogenesis of Rheumatoid Arthritis. Immunity. 2012;46(2):183-96.

28. Schellekens GA, Visser H, de Jong BA, van den Hoogen FH, Hazes JM, Breedveld FC, et al. The diagnostic properties of rheumatoid arthritis antibodies recognizing a cyclic citrullinated peptide. Arthritis Rheum. 2000;43(1):155-63.

29. Kerkman PF, Kempers AC, van der Voort EIH, van Oosterhout M, Huizinga TWJ, Toes REM, et al. Synovial fluid mononuclear cells provide an environment for long-term survival of antibody-secreting cells and promote the spontaneous production of anti-citrullinated protein antibodies. Ann Rheum Dis. 2016;75(12):2201-7. 
30. Terao C, Asai K, Hashimoto M, Yamazaki T, Ohmura K, Yamaguchi A, et al. Significant association of periodontal disease with anti-citrullinated peptide antibody in a Japanese healthy population-The Nagahama study. J Autoimmun. 2015;59:85-90.

31. van Zanten A, Arends S, Roozendaal C, Limburg PC, Maas F, Trouw $\mathrm{LA}$, et al. Presence of anticitrullinated protein antibodies in a large population-based cohort from the Netherlands. Ann Rheum Dis. 2017;76(7):1184-90.

32. Harvey GP, Fitzsimmons TR, Dhamarpatni AA, Marchant C, Haynes DR, Bartold PM. Expression of peptidylarginine deiminase-2 and -4, citrullinated proteins and anti-citrullinated protein antibodies in human gingiva. J Periodontal Res. 2013;48(2):252-61.

33. Reichert S, Schlumberger W, Dahnrich C, Hornig N, Altermann W, Schaller $H G$, et al. Association of levels of antibodies against citrullinated cyclic peptides and citrullinated alpha enolase in chronic and aggressive periodontitis as a risk factor of Rheumatoid arthritis: a case control study. J Transl Med. 2015;13:283.

34. Mohamad WMW, Jia SK, Ghazali WSW, Taib H. Anti-cyclic citrullinated peptide antibody and periodontal status in rheumatoid arthritis patients. Pak J Med Sci. 2018:34(4):907-12.

35. Rosenstein ED, Greenwald RA, Kushner LJ, Weissmann G. Hypothesis: the humoral immune response to oral bacteria provides a stimulus for the development of rheumatoid arthritis. Inflammation. 2004;28(6):311-8.

36. D'Aiuto F, Parkar M, Andreou G, Suvan J, Brett PM, Ready D, et al. Periodontitis and systemic inflammation: control of the local infection is associated with a reduction in serum inflammatory markers. J Den Res. 2004;83(2):156-60.
37. Leira Y, Martin-Lancharro P, Blanco J. Periodontal inflamed surface area and periodontal case definition classification. Acta Odontol Scand. 2018;76(3):195-8.

38. Vaithilingam RD, Taiyeb-Ali TB, Yusuf R. Aggregatibacter actinomycetemcomitans and Prevotella intermedia in advanced chronic periodontitis patients. Ann Dent UM. 2010;17:1-8.

39. Gupta A, Kaushik R, Kaushik RM, Saini M, Kakkar R. Association of anti-cyclic citrullinated peptide antibodies with clinical and radiological disease severity in rheumatoid arthritis. Curr Rheumatol Rev. 2014;10(2):136-43.

40. Papadopoulos NG, Tsiaousis GZ, Pavlitou-Tsiontsi A, Giannakou A, Galanopoulou VK. Does the presence of anti-CCP autoantibodies and their serum levels influence the severity and activity in rheumatoid arthritis patients? Clin Rev Allergy Immunol. 2008;34(1):11-5.

41. Landmann T, Kehl G, Bergner R. The continuous measurement of antiCCP-antibodies does not help to evaluate the disease activity in anti-CCPantibody-positive patients with rheumatoid arthritis. Clin Rheumatol. 2010;29(12):1449-53.

42. Wolfe F. Comparative usefulness of C-reactive protein and erythrocyte sedimentation rate in patients with rheumatoid arthritis. J Rheumatol. 1997;24(8):1477-85.

\section{Publisher's Note}

Springer Nature remains neutral with regard to jurisdictional claims in published maps and institutional affiliations.
Ready to submit your research? Choose BMC and benefit from:

- fast, convenient online submission

- thorough peer review by experienced researchers in your field

- rapid publication on acceptance

- support for research data, including large and complex data types

- gold Open Access which fosters wider collaboration and increased citations

- maximum visibility for your research: over 100M website views per year

At BMC, research is always in progress.

Learn more biomedcentral.com/submissions 